\title{
Interpretation of the Mass Change Behavior in the Binary Monolayer of Hydroquinone-tethered Alkylthiol and Aminoalkylthiol
}

\author{
Kyoungia Seo, Il Cheol Jeon, Hun-Gi Hong, ${ }^{\dagger}$ and Wonchoul Park ${ }^{\dagger}$ \\ Department of (hemistm, ('hombth National tinversity, Jeonhth 561-756, Norea \\ ${ }^{\dagger}$ Department of ('hemisty. Sejong Lniversin, Seoul 143-747, Korea \\ Received heptember 11, 2002
}

Key Words : Hydroquinone-lethered SAM. Mixed SAM. Flectromicrogravimetry Bisullate

The hydroquinone/quinone redox couple has drawn much interests for a long time because of their importance in biological activities. The electrochemistry of lydroquinonetethered alkylthiol self-assembled monolayers (SAMs) has been studied previously and many characteristics including structural and vibrational properties. ${ }^{23}$ electron transfer kinetics. ${ }^{45}$ and mass change properties" were reported. By the way the monolayers with a large tail group are usually packed with disorders depending on the bulkiness of the tail group. Disordered monolayers have many defects that allow penetration of electrolytes and solvent molecules into the monolayer. For this reason a monolayer with a large tail group shows mass changing belaviors originated from the redox reaction of the monolayer and extra mass changes due to counterions adsorbed onto the SAM surface. Mixed monolayers formed from simple alkylthiol molecules and the surfactant bearing large tail groups are known to show an enhanced packing and ordering. ${ }^{-9}$ Well-prepared mixed monolayers usually show that the penetration of the electrolytes and solvents is excluded.

The mass change property of the mixed SAMs of 2-(nmercaptodecyl)hy droquinone $\left(\mathrm{H}_{2} \mathrm{Q}\left(\mathrm{CH}_{2}\right)_{11} \mathrm{SH}\right.$ : abbr. $\mathrm{H}_{2} \mathrm{QC}$ $10 \mathrm{SH})$ and 1-Aminoundecylthiol $\left(\mathrm{NH}_{2}\left(\mathrm{CH}_{2}\right)_{1} \mathrm{SH}\right.$ : abbr. $\mathrm{NH}_{2} \mathrm{Cl}$ 1SH) has been examined by electromicrogravimetry in the sulfuric acid solution. lt shows a mass increase upon oxidation of hydroquinone moiety while the mass decreased in case of the $\mathrm{H}_{2} \mathrm{QClOSH}$ monolayer or the mixed monolayer of $\mathrm{H}_{2} \mathrm{QCl}$ (OSH and dodecy lthiol $\left(\mathrm{CH}_{3}\left(\mathrm{CH}_{2}\right)_{11} \mathrm{SH}\right.$; abbr. $\mathrm{C} 12 \mathrm{SH}$ ). In this article. the reason for this umusual behavior is mainly due to an intake of bisulfate ions bound to a carbonyl group of quinone and two amine groups of $\mathrm{NH}_{2} \mathrm{Cl} 1 \mathrm{SH}$ molecules as a diluent in the mixed SAM.

\section{Experimental Section}

Materials. 2-(n-mercaptodecyl)hydroquinone was synthesized according to the procedure described in the literature ${ }^{4.5}$ and stored in a cool and dark place under an atmosphere of dry Argon. Absolute EtOH (HPLC grade. Fisher) and 1dodecylthiol (98\%. Aldrich) were used as received. 1Aminoundecylthiol $\left(\mathrm{NH}_{2}\left(\mathrm{CH}_{2}\right)_{1} \mathrm{SH}\right)^{1 \text { i) }}$ was donated from Prof. Dongjin Yoo (Seonam Univ.). Electrolyte solutions of

*Corresponding Author: e-mail: jojeong gimoak chonbuk ackr
$\mathrm{H}_{2} \mathrm{SO}_{1}(97 \%$. Showa) and $\mathrm{KOH}(95+\%$. Aldricl $)$ were prepared with de-ionized water (resistivity $>18 \mathrm{MS} \mathrm{cm}$ ). All the electrochemical measurements were carried out at room temperature after the electrolyte solution was deaerated by purging Argon gas for at least 10 min.

Apparatus. A commercial EQCM (SHln EQCN 1000. Korea) was used for all electrochemical measurements. The electrochemical cell consisted of a quartz crystal gold electrode as the working electrode. a Pt wire as the counter electrode, and an $\mathrm{Ag} \mid \mathrm{AgCl}($ sat'd) electrode as the reference electrode. The gold film electrode coated on $10 \mathrm{MHz}$ quartz crystal (ICM Co., OK. USA or Morion lnc., Petersburg. Russia) was chemically cleaned in a piranha solution ( $98 \%$ $\mathrm{H}_{2} \mathrm{SO}_{1}$ and $30 \% \mathrm{H}_{2} \mathrm{O}_{2} .2: 1$ by volume: Use with caution!) or electrochemically polished in $0.1 \mathrm{M} \mathrm{H}_{2} \mathrm{SO}_{4}$. The mass sensitivity of $10 \mathrm{MHz}$ quartz cry stals is calculated to be 4.42 $n g \mathrm{~cm}^{-2} \mathrm{~Hz}^{-1}$. It was rinsed with deionized water. ethanol. and then dried with a stream of nitrogen gas. The monolayers were formed on the Au electrode by soaking the electrode in an ethanol solution containing $1 \mathrm{mM}$ surfactant for 2 h. followed by rinsing thoroughly with ethanol and drying with a stream of nitrogen gas, and then used in electrochemical measurements. For the formation of a mixed monolayer, a mixture solution of $\mathrm{H}_{2} \mathrm{QCIOSH} / \mathrm{CI} 2 \mathrm{SH}$ or $\mathrm{NH}_{2} \mathrm{Cl} 1 \mathrm{SH}$ as a diluent ( $1: \mathrm{l}$ in molar ratio) was used while the total concentration of thiols was kept to be $1 \mathrm{mM}$. The surface coverage of hydroquinone was calculated from the charge obtained by integration of voltammetric peaks.

\section{Results and Discussion}

Figure 1 exhibits the cyclic voltammogram and the mass change response of the hydroquinone-tethered decylthiol $\left(\mathrm{H}_{2} \mathrm{QCl}\right.$ l0SH) monolayer in $0.05 \mathrm{M}$ sulfuric acid with the surface coverage of $5.65 \times 10^{-1 i} \mathrm{~mol} \mathrm{~cm} \mathrm{~cm}^{-2}$. It shows a couple of symmetric redox peaks of hydroquinone moiety with a mass decrease during oxidation of the redox center and returning to the original mass value in the reduction scan. Since there is no change in charge for the redox reaction of hydroquinone moiety. there is no reason to expect for counterions to move into or out of the monolayer. Thus the mass decrease in the oxidation process is obviously due to the ejection of protons hydrated with water molecules regarding the redox mechanism of the hydroquinone- 


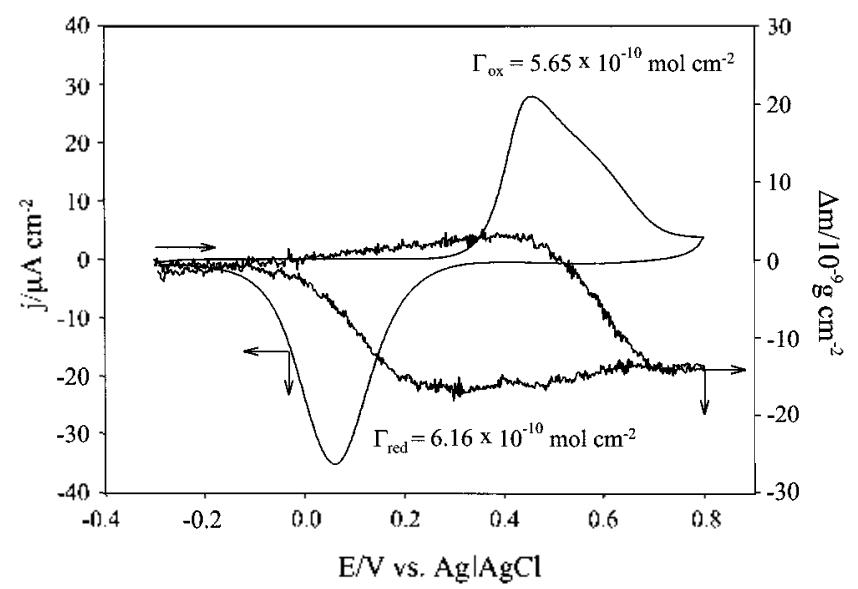

Figure 1. CV and mass change of $\mathrm{H}_{2} \mathrm{QC} 1 \mathrm{OSSH}$ monolaver moditied gold electrode. Coverage: $\Gamma_{1 \mathrm{n}}=5.65 \times 10^{-10} \mathrm{~mol} \mathrm{~cm}^{-2}$ : Lilectrolyta: $0.05 \mathrm{M} \mathrm{ll}_{\mathrm{S}} \mathrm{SO}$. : Setan rate: $50 \mathrm{~m} \mathrm{Vs}$ !

quinone system."

In the oxidation process. however. a close examination reveals the baseline in the mass change response slightly arises as the electrode potential shifts in the positive direction. As described in our previous report. it is explained by the adsorption of counteranions onto the gold surface.
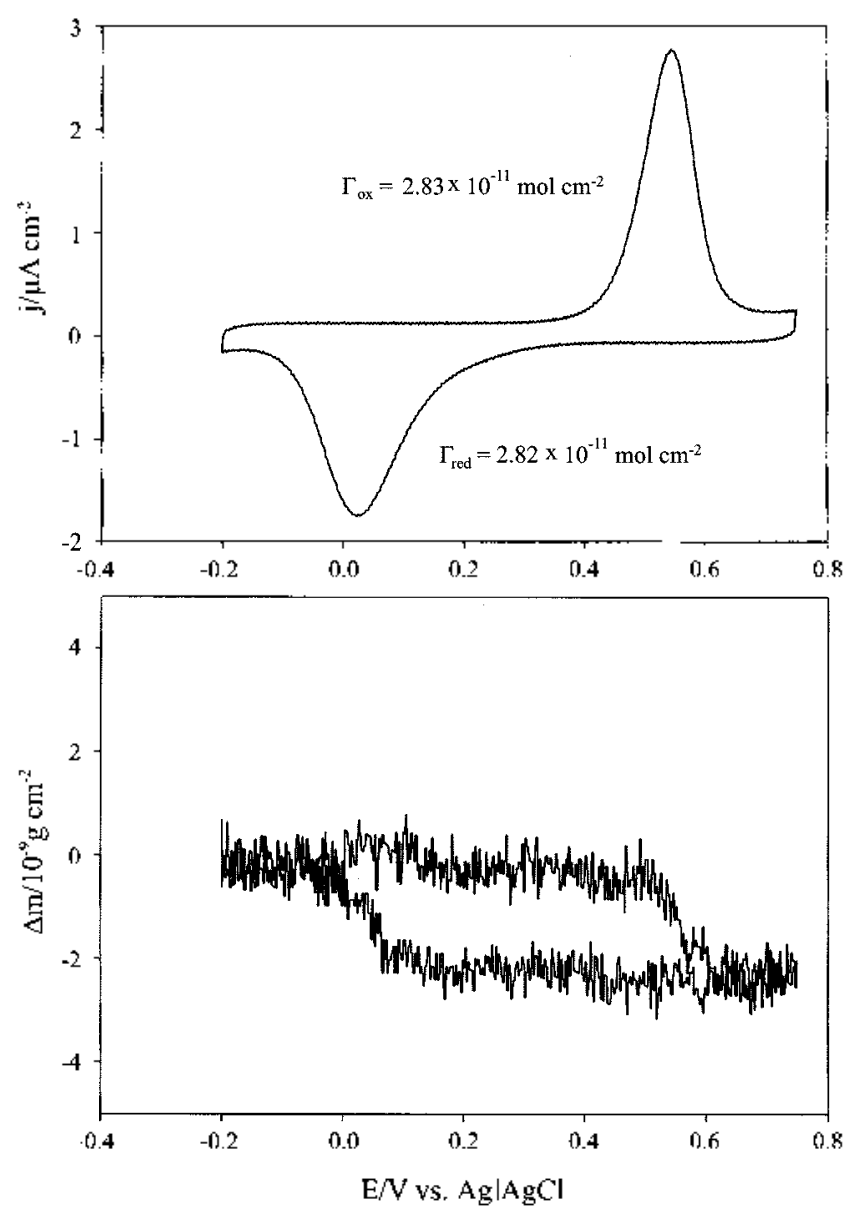

Figure 2. CV and mass shange of the binary monolaver of

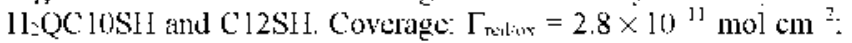
F. lectrol: te: $0.05 \mathrm{M} \mathrm{H}_{2} \mathrm{SO}_{4}$ : Scan rate: $50 \mathrm{mV} \mathrm{s}^{-1}$ which is penetrated into the loosely packed SAM. ${ }^{11}$ In case of a lower coverage. the baseline is much steeper than that in more compact SAM.

In the binary SAM of $\mathrm{Cl} 2 \mathrm{SH}$ and $\mathrm{H}_{2} \mathrm{QClOSH}$. the mass change is mainly due to an ejection of protons hydrated with water as shown in Figure 2. The coverage of $\mathrm{H}_{2} \mathrm{QClOSH}$ is ca. $2.8 \times 10^{-11} \mathrm{~mol} \mathrm{~cm}^{-2}$ and the mass change is about $2 \mathrm{ng}$ $\mathrm{cm}^{-2}$ which is equivalent to $c a .71 \mathrm{~g} \mathrm{~mol}^{-1}$. It is similar to the responses from the $\mathrm{H}_{2} \mathrm{QCISH}$ or $\mathrm{H}_{2} \mathrm{QSH}$ SAMs. ${ }^{6}$

However, the mass change behavior in the binary monolayer of $\mathrm{NH}_{2} \mathrm{CllSH}$ and $\mathrm{H}_{2} \mathrm{QClOSH}$ is opposite to those from the monolayers described above. The cyclic voltammogram and the corresponding mass change response of the binary monolayer of $\mathrm{NH}_{2} \mathrm{Cl} I \mathrm{SH}$ and $\mathrm{H}_{2} \mathrm{QClOSH}$ in $0.05 \mathrm{M}$ sulfuric acid are exhibited in Figure 3. In this figure the voltammogram and the mass change for the $\mathrm{NH}_{2} \mathrm{Cl} I \mathrm{SH}$ SAM are also represented. which look like background signals. As expected there is no remarkable mass clange in the $\mathrm{NH}_{2} \mathrm{C}$ IISH SAM.

In the mixed monolayer. however. the mass clange increases with the potential increase. The mass change per unit charge is found to be about $40 \pm+\mathrm{g} \mathrm{mol}^{-1}$. It is

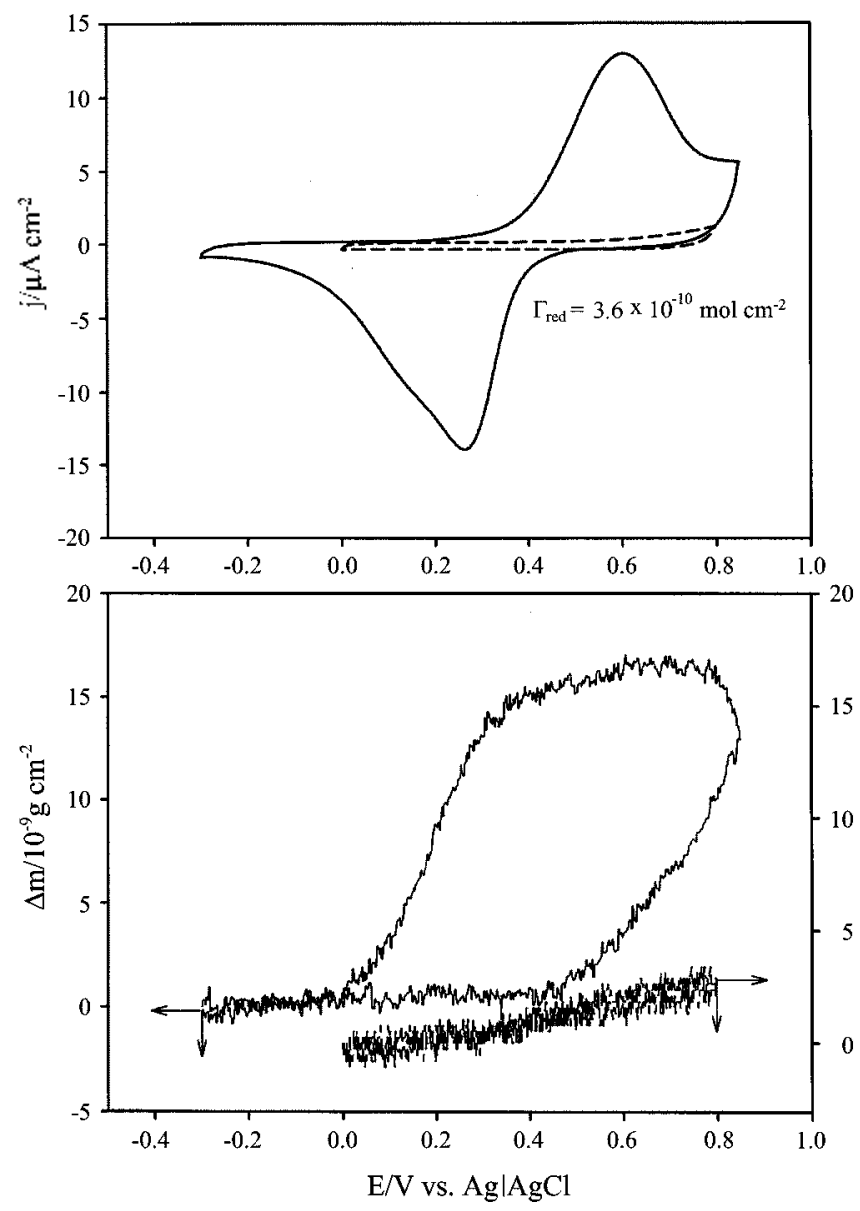

Figure 3. CV and mass change responsi of $\mathrm{NH}_{2} \mathrm{C}$ I ISI I monolayer (broken line for $\mathrm{CV}$ and lower skewed response for mass change) and the binary monolaver of $\mathrm{H}_{2} \mathrm{QC} 10 \mathrm{SH}$ and $\mathrm{NH}_{2} \mathrm{Cl} 1 \mathrm{SH}$. Coverage: $\Gamma_{\text {rex }}=3.6 \times 10^{\text {io }} \mathrm{mol} \mathrm{cm}{ }^{2}$. Liectrolyte: $0.05 \mathrm{M} \mathrm{H}_{2} \mathrm{SO}_{1}$; Scan rate: $50 \mathrm{mVs}_{\mathrm{s}}$. 


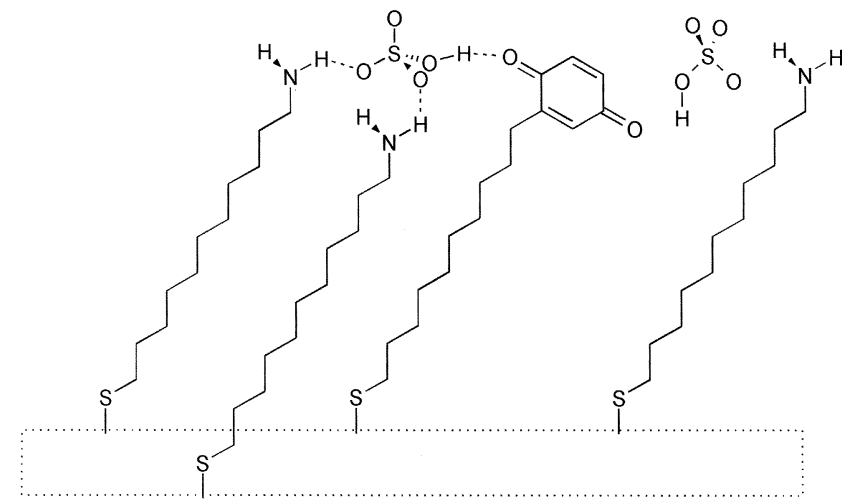

Figure 4. Schematic diagram sugessting an intake of bisultate anjions bound to a carbonyl group through hydrogen bonding and two neighboring amine groups by coordination bonding.

obviously contrary to the response of the $S A M$ of $\left[\mathrm{I}_{2} \mathrm{QC}\right.$ 10S] $\mathrm{l}$ or the mixed SAM of $\left.\mathrm{H}_{2} \mathrm{QC} 10 \mathrm{SJ}\right]$ and $\mathrm{C} 12 \mathrm{SH}$ $\mathrm{S} \wedge \mathrm{M}$. Considering the mass change responses of SAMs described above, the mass increase arises only from the mixed SAM composed of I $1_{2} \mathrm{QC} 10 \mathrm{SH}$ and $\mathrm{NH}_{2} \mathrm{C} 1 \mathrm{ISI}$. In the presence of bisulfate, the most plausible explanation for the mass increase is that a bisulfate anion binds to the carbonyl group. It can be interpreted as the binding of bisulfate ion through hydrogen bonding with carbonyl oxygen of quinone and intermolecular coordination with amine group near the quinone-lethered molecule. Since the alkyl chain length of $\mathrm{J}_{2} \mathrm{QCIOSH}$ and $\mathrm{NJ}_{2} \mathrm{CI} 1 \mathrm{SH}$ is quite close each other, the bisulfate ion does not experience difliculty in making a coordination bond with amine and carbonyl oxygen functionalities. The hydrogen binding scheme is given in Figure 4. It is expected that two neighboring amine groups and a carbonyl group coordinate a bisulfate ion. llowever, it may not be possible that the oxygen atom in opposite position participates in coordination of a bisulfate ion because a geometric disadvantage for coordination and repulsive interaction between a charged bisulfate ion and the hydrophobic layer are expected.

It is a very similar result to that observed in a study of ion selective clectrode. According to Jcon ef al., ${ }^{12}$ a bisullate anion is caught by a calixcrown molecules connected with urea functional groups via the hydrogen bonding with oxygen of oxidized quinone moiety and the coordination bonding between oxygen atoms of bisullate and amine groups in urea functional groups in the same molecule.

Regarding the mass change per unit chatge, Scherson et $a^{6}{ }^{6}$ suggested that three water molccules are bound to each hydroxyl group in hydroquinone and two water molecules are bound 10 each carbonyl group upon oxidation in a solution of perchloric acid. $A$ s a result the mass decrease in the oxidation is conlirmed experimentally to be $38 \mathrm{~g} \mathrm{~mol}^{-1}$. This value is equivalent to the loss of two protons and two water molecules.

llowever, it is expected in the presence of bisulfate ions that a water molecule bound to a carbonyl group in quinone be replaced with a bisulfate ion resulting in the loss of a water molecule and the subsequent acquirement of a bisulfate ion. The additional contribution from the binding of a bisullate ion is an increase in mass of $79 \mathrm{~g} \mathrm{~mol}^{-1}$ which is equivalent to the intake of a bisulfate ion $\left(97 \mathrm{~g} \mathrm{~mol}^{-1}\right)$ and the simultaneous release of a water molecule $\left(18 \mathrm{~g} \mathrm{~mol}^{-1}\right)$. Consequently it is possible to expect a net mass change of 41 $\mathrm{g} \mathrm{mol}^{-1}$ when the hydroquinone moieties in a mixed SAM of $\left.\mathrm{I}_{2} \mathrm{QC} / 0 \mathrm{~S}\right][$ and $\mathrm{N}] \mathrm{I}_{2} \mathrm{CI}$ 1S] [ are oxidized in the presence of bisulfate anion. This value is well matched with the observed mass change per unit charge $40 \pm 4 \mathrm{~g} \mathrm{~mol}^{-1}$.

Finally we expect that it would be possible to utilize the mixed monolayer of $\left.]_{2} \mathrm{QC} 10 \mathrm{~S}\right]\left[\right.$ and $\mathrm{N}_{2}{ }_{2} \mathrm{CIISH}$ as a very sensitive bisulfate ion sensor. Further experiments for determining sensitivity and detection limit are in progress.

Acknowledgment. This work was supported by grant No. R01-1999-000-00038-0 from the Basic Research Program of the Korea Science \& Enginecring Foundation.

\section{References}

1. Chambers. I. Q. In The Chemism of the Ouinonoid Compounds: Patai. S. Ed.: Wiley: New York. 1974: p 737.

2. Yc. S.: Yashiro, A.: Sato. Y.: Losaki, K. I. Chem. Soc. Farada Trans. 1996. 92.3813.

3. Soriaga. M. P': I Jubbard. A. I. J. th Chem. Soc 1982. /1/4.3937.

4. IJong. IJ.-G.: l'ark. W.: Yu. E. J. Electroumen. Chem. 1999. 476. 177.

5. Hong. H.-G.; Park. W. Langmitr 2001. /7. 2485.

6. Mo. Y.: Sandifer. M.: Sukenik, C.: Barriga R. I.: Soriaga. M. P.: Scherson. D. Lemgmitr 1995. //. 4626

7. Guionmar. A. J.: Guthrie. J. T.: Evens. S. D. Lemgmir 1999. /5. 1198

8. Atre, S. V.: I.iedberg. B.: Allara D. I.. Langmuir 1995. I/. 3882,

9. Bang. G. S.: Jeon, I. C. Bull. Korean Chem. Soc, 2001, 22, 281.

10. Takehaha, K.; Takemura. H.: Ide. Y. Electrochim .1cta 1994, 39. 817.

11. Seo. K.: Jeon. I. C.: Yoo. D. J. submilted.

12. (a) Kang. \$. O.: Oh. I. M.: Yang. Y. S.: Chun. Y. C.: Jeon. S.: Nam. K. C. Bull. Korean (hem. Soc. 2002. 23. 145. (b) Cho. E. I.: Hwatng. S. S.: Oh. J. M.: Lee. H. K.: Jeon. S.: Nam. K. C. Bull. Korean (hem. Soc. 2001. 22. 782. (c) leong. H.: Choi. E. M.: Kang. S. O.: Niam. K. C... Jeon. S. J. Electroumal Chem. 2000. 485. 154. (d) Niam. K. C.. Kang. S. O.: Jeong. II. S.: Jeon. S. Tetrahedron Lett. 1999. 4fo. 7343 . 